http://jmscr.igmpublication.org/home/

ISSN (e)-2347-176x ISSN (p) 2455-0450

crossref DOI: https://dx.doi.org/10.18535/jmscr/v7i11.133

Journal Of Medical Science And Clinical Research

IGM Publication

An Official Publication of IGM Publication

\title{
Histomorphological Analysis of Invasive Breast Carcinoma in a Tertiary Care Center
}

\author{
Authors \\ Dr Lavanya $\mathrm{N}^{1}$, Dr Geetha Devadas ${ }^{2 *}$ \\ ${ }^{1}$ Assistant Professor, ${ }^{2}$ Professor, Institute of Pathology, Madras Medical College \\ *Corresponding Author \\ Dr Geetha Devadas \\ Professor, Institute of Pathology, Madras Medical College
}

\begin{abstract}
Background: Breast carcinoma is the most common malignant tumor and also one of the leading cause of the carcinoma deaths in women. There are many prognostic factors established for breast carcinoma. The most important prognostic factors of breast cancer are tumor size, histological grade and lymph nodal stage.

Objectives: To study the relative frequency, distribution and histomorphological features of breast carcinoma in the study group.

Materials and Methods: A total of 165 breast carcinoma specimens (Mastectomy) were enrolled between the period of September 2014 to August 2016. Age, tumor size, tumor grade, necrosis, associated breast lesions, lymph node involvement, lymphovascular invasion, lymphocytic response, skin infiltration, margin status were analyzed.

Results: Median age of the study group was 49 years. Invasive Carcinoma - Not Otherwise Specified was the commonest type, 38 cases (23\%) had tumor less than $2 \mathrm{~cm}, 99$ cases (60\%) were of 2 to $5 \mathrm{~cm}$ in size and 28 cases $(17 \%)$ were more than $5 \mathrm{~cm}$ in size, $56.4 \%$ were grade 2 tumors. Node positive cases were 58.25 $\%(n=96)$, Skin infiltration was seen in $6.1 \%(n=10)$, necrosis was seen in $47.3 \%(n=78)$, Lymphovascular invasion was seen in $74.5 \%$ ( $n=123)$, Positive margins were noted in $7.9 \%(n=13)$. Lymphocytic infiltration response was seen in $74.5 \%(n=123)$.

Conclusion: Invasive carcinoma was the most common type. Incidence was more common at younger age group as compared to western population. More than half of the patients presented with lesser tumor size, lymph nodal metastasis, lesser grade and more lymphocytic response. This study population had better prognostic factors.
\end{abstract}

\section{Introduction}

Breast carcinoma is the most common malignant disease and the leading cause of cancer deaths in females with more than 1 million cases being reported globally annually. ${ }^{[1]}$ In United States, around 1 lakh new cases are diagnosed annually and around thirty thousand women die due to breast carcinoma. In India, the crude incidence 
rate of breast carcinoma is 85 per one lakh women per year $^{[2]}$

Breast cancer is more common in 50-60 years of age constituting $69 \%$ of breast cancer. India is rapidly moving towards industrialization which results in lifestyle changes. This is probably the reason for increase in breast cancer incidence in India. The most important prognostic factors of breast cancer are tumor size, histological grade and lymph nodal stage.

The evaluation of the prognostic factors to provide the prophecy of outcome has become an important role of the histopathologist in handling and reporting the invasive breast carcinomas. We aimed to identify the relative frequency and distribution of breast carcinoma and to study the histomorphological features of breast carcinoma including histological subtypes, grade, lymph node status, lymphovascular invasion, lymphocytic response, necrosis and skin infiltration in our study population.

\section{Materials and Methods}

This study is a descriptive prospective and retrospective study of Primary breast carcinomas conducted in the Institute of Pathology, Madras Medical College and Rajiv Gandhi Government General hospital, Chennai during the period between September 2014 to August 2016. The study includes all modified radical mastectomy specimens of breast carcinomas. All small biopsies and recurrent tumors were excluded from the study.

Detailed history of the cases regarding age, sex, side of the breast, type of procedure, details of gross characteristics such as tumor size, nodal status were obtained for those 165 cases from surgical pathology records. Formalin fixed tissue were cut, processed and paraffin embedded. Four $\mu$ mthick sections of the paraffin tissue blocks were cut and stained with eosin and hematoxylin. Slides were collected from slide filing and were reviewed and graded using the Nottingham modification of the Scarff Bloom Richardson Grading system and they were further evaluated for the presence of necrosis, lymphocytic response, lymphovascular invasion and skin infiltration. Staging of tumor and nodal involvement was done using TNM staging system, AJCC, ed .8.

\section{Results}

The total number of breast carcinomas enrolled in this study period was 165 cases. The highest incidence of breast cancers was found in the age group of 41-50 years. The median age of the patient in this study was 49 . The youngest age of presentation of breast cancer was 30 years in this study. 77 cases of primary breast carcinomas were reported in left breast and 88 cases were reported in right breast. 66 cases of breast carcinoma were in upper outer quadrant.

Thirty eight cases (23\%) had tumor less than 2 $\mathrm{cm}, 99$ cases $(60 \%)$ were of 2 to $5 \mathrm{~cm}$ in size and 28 cases $(17 \%)$ were more than $5 \mathrm{~cm}$ in size.

Commonest histopathological subtype in this study was IDC NOS which constituted $93.9 \%$ $(n=155)$ of cases and other subtypes were metaplastic carcinoma $(n=3)$, mucinous carcinoma $(\mathrm{n}=5)$, apocrine carcinoma $(\mathrm{n}=1)$ and intracystic papillary carcinoma $(n=1)$.

Tumor grade was done according to modified SBR grading system, low grade (grade 1 and 2) includes $83.7 \%(\mathrm{n}=138)$ and high grade (grade 3$)$ seen in $12.1 \%(\mathrm{n}=20)$ only.

62 cases $(37.6 \%)$ had upto 3 nodes with metastatic carcinomatous deposits, 25 cases $(15.2 \%)$ had 4 to 9 involved nodes, 9 cases $(5.5 \%)$ had more than 10 involved nodes, while 69 cases $(41.8 \%)$ had no nodal involvement.

Positive margins were noted in $7.9 \%(n=13)$ and adequate margins were noted in $92.1 \%(n=152)$ cases.

Lymphovascular invasion seen in $74.5 \%(\mathrm{n}=123)$ and absent in $25.5 \%(\mathrm{n}=42)$ cases. Lymphocytic infiltration was seen in 123 cases $(74.5 \%) .78$ out of 165 cases $(47.3 \%)$ had necrosis. Skin infiltration was seen in 10 out of 165 cases, which constituted $6.1 \%$. 


\begin{tabular}{|c|c|c|c|}
\hline CHARACTER & $\mathrm{n}(\%)$ & CHARACTER & $\mathrm{n}(\%)$ \\
\hline SIDE & & TYPES & \\
\hline RIGHT & $88(53.3 \%)$ & INVASIVE CA NOS & $155(93.9 \%)$ \\
\hline LEFT & $77(46.7 \%)$ & METAPLASTIC CA & $3(1.8 \%)$ \\
\hline QUADRANT & & IDC WITH MUCINOUS CA & $5(3.0 \%)$ \\
\hline UOQ & $66(40 \%)$ & APOCRINE CA & $1(0.6 \%)$ \\
\hline UIQ & $25(15.2 \%)$ & INTRACYSTIC PAPILLARY CA & $1(0.6 \%)$ \\
\hline LOQ & $22(13.3 \%)$ & MARGINS & \\
\hline LIQ & $17(10.3 \%)$ & PRESENT & $13(7.9 \%)$ \\
\hline CENTRAL & $35(21.2 \%)$ & ABSENT & $152(92.1 \%)$ \\
\hline SIZE & & LYMPHOVASCULAR INVASION & \\
\hline T1 & $38(23.0 \%)$ & PRESENT & $95(57.6 \%)$ \\
\hline T2 & $99(60 \%)$ & ABSENT & $70(42.4 \%)$ \\
\hline T3 & $28(17 \%)$ & LYMPHOCYTIC RESPONSE & \\
\hline NODAL & & PRESENT & $123(74.5 \%)$ \\
\hline N0 & $69(41.8 \%)$ & ABSENT & $42(25.5 \%)$ \\
\hline N1 & $62(37.6 \%)$ & SKIN INFILTRATION & \\
\hline N2 & $25(15.2 \%)$ & PRESENT & $10(6.1 \%)$ \\
\hline N3 & $9(5.5 \%)$ & ABSENT & $155(93.9 \%)$ \\
\hline GRADE & & NECROSIS & \\
\hline UNKNOWN & $7(4.2 \%)$ & PRESENT & $78(47.3 \%)$ \\
\hline GRADE I & $45(27.3 \%)$ & ABSENT & $87(52.7 \%)$ \\
\hline GRADE II & $93(56.4 \%)$ & ASSOCIATED LESION & \\
\hline GRADE III & $20(12.1 \%)$ & NIL & $24(14.5 \%)$ \\
\hline & & FIBROCYSTIC DISEASE & $95(57.6 \%)$ \\
\hline & & DUCTAL CARCINOMA INSITU & $30(18.2 \%)$ \\
\hline & & ADENOSIS & $5(3.0 \%)$ \\
\hline & & EPITHELIAL HYPERPLSIA & $3(1.8 \%)$ \\
\hline & & $2(1.2 \%)$ \\
\hline & & $6(3.6 \%)$ \\
\hline
\end{tabular}

Distribution of Histological Type

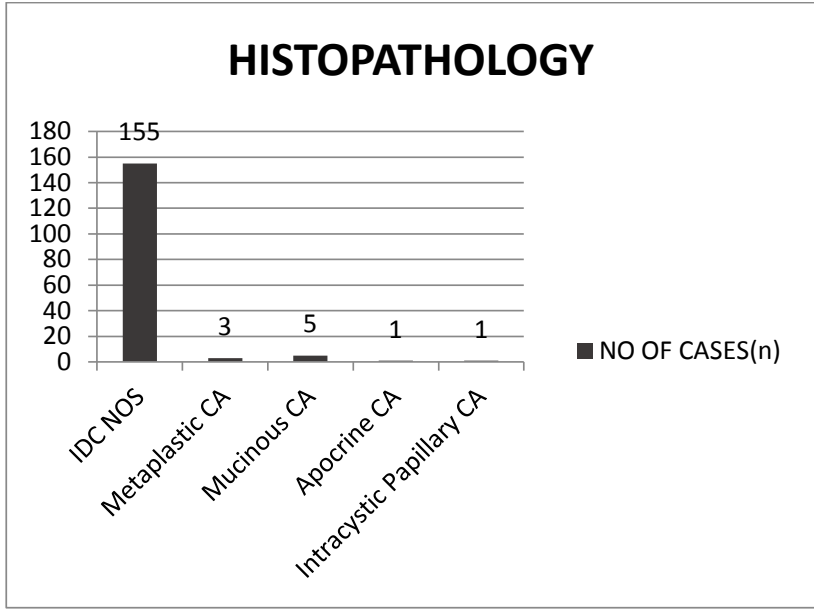

Distribution of Size of the Tumor

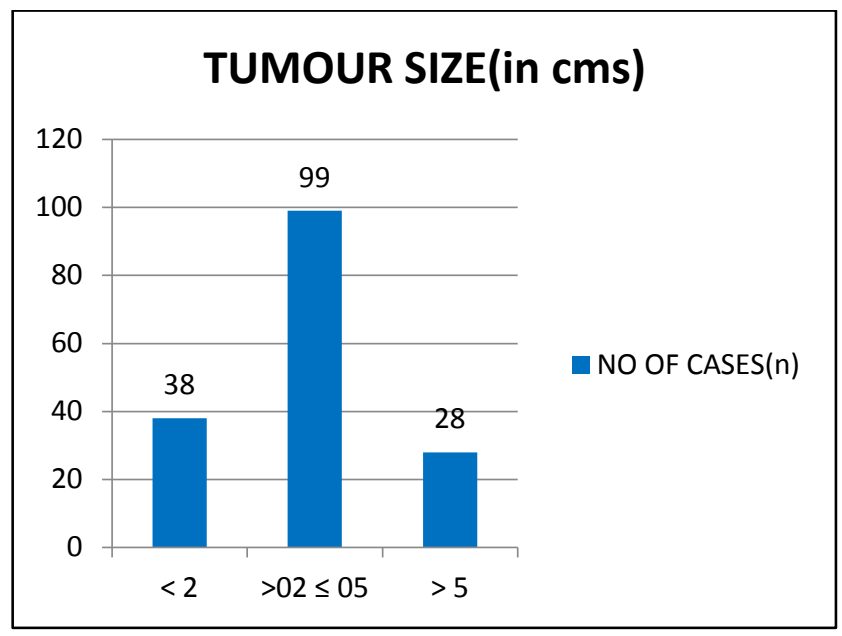




\section{Distribution of Histological Grade}

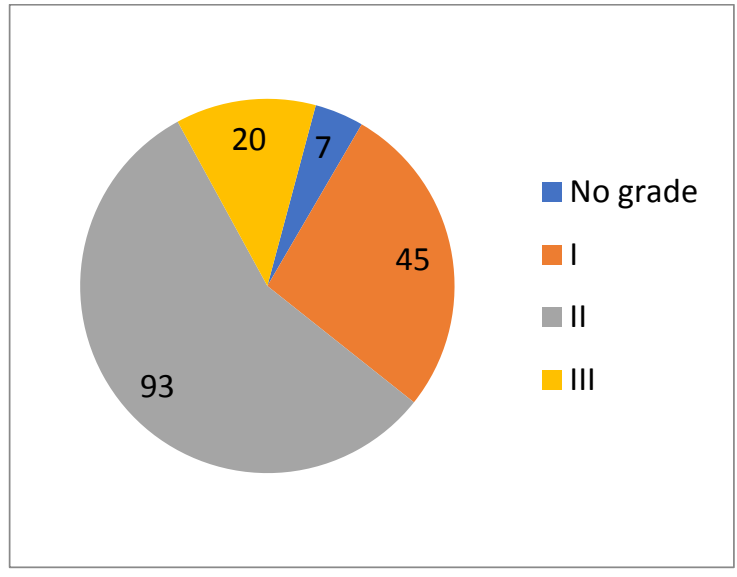

Distribution of Lymph Node Metastasis in Breast Cancers

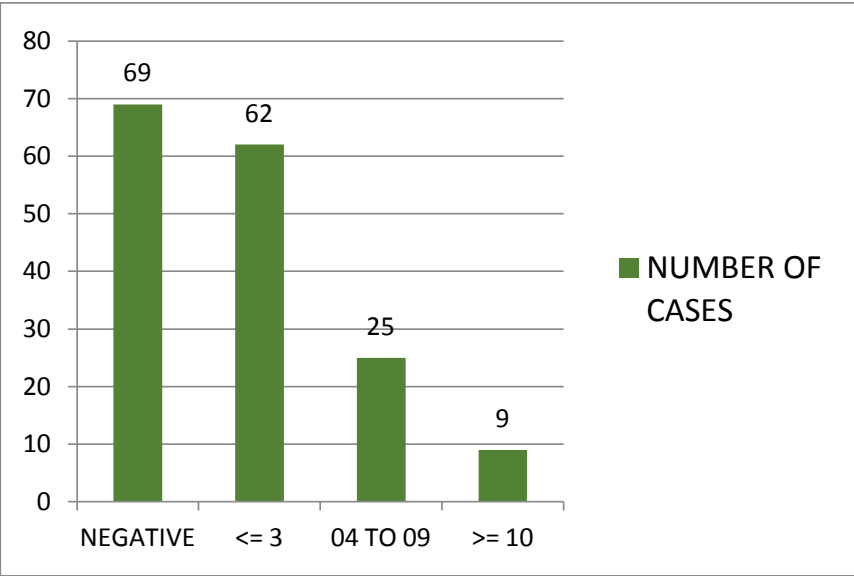

Distribution of Lympho Vascular Invasion in Breast Cancer

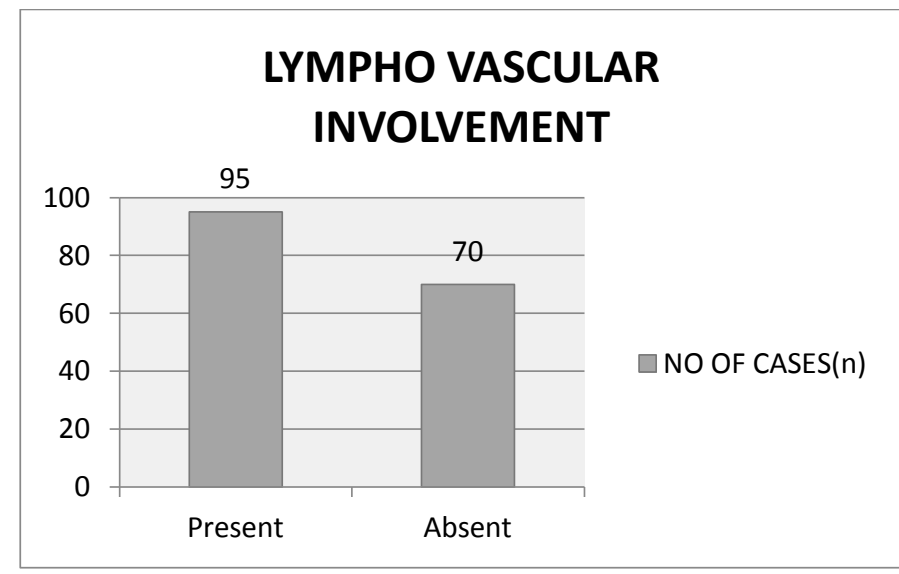

\section{Ductal Carcinoma of Breast}

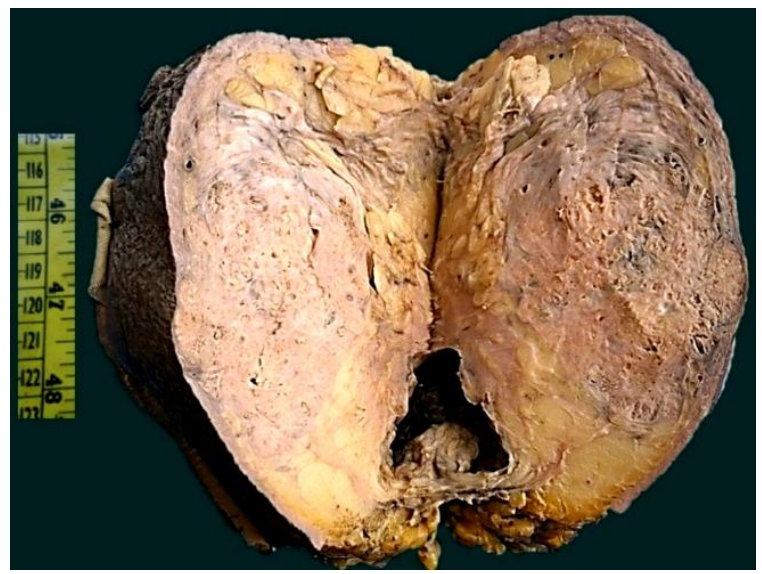

Figure 6. Infiltrative grey white, firm growth with irregular margins

\section{IDC Grade 1}

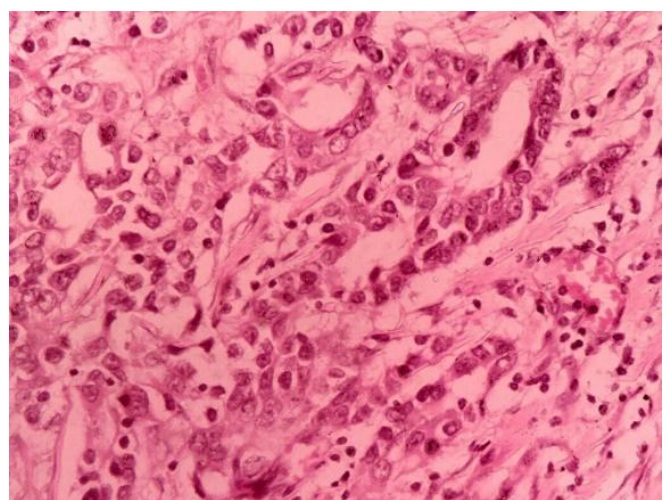

Figure.7.Malignant duct epithelial cells arranged in tubules with mild nuclear pleomorphism (400x)

\section{IDC Grade 2}

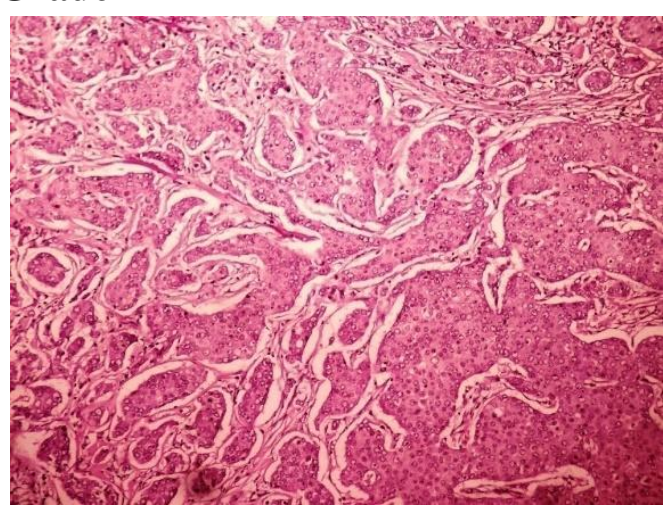

Figure.8 Malignant duct epithelial cells in tubules and sheets with moderate nuclear pleomorphism $(100 \mathrm{X})$ 


\section{IDC Grade 3}

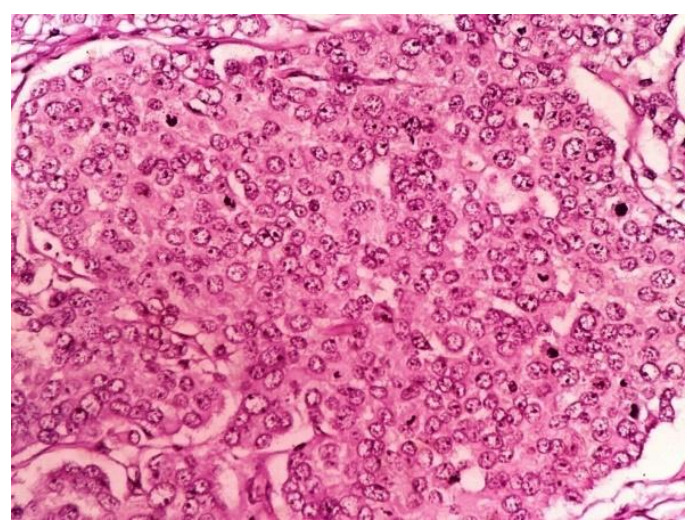

Figure.9. Malignant duct epithelial cells in sheets with marked nuclear pleomorphism and increased mitosis (400x)

\section{Mucinous Carcinoma}

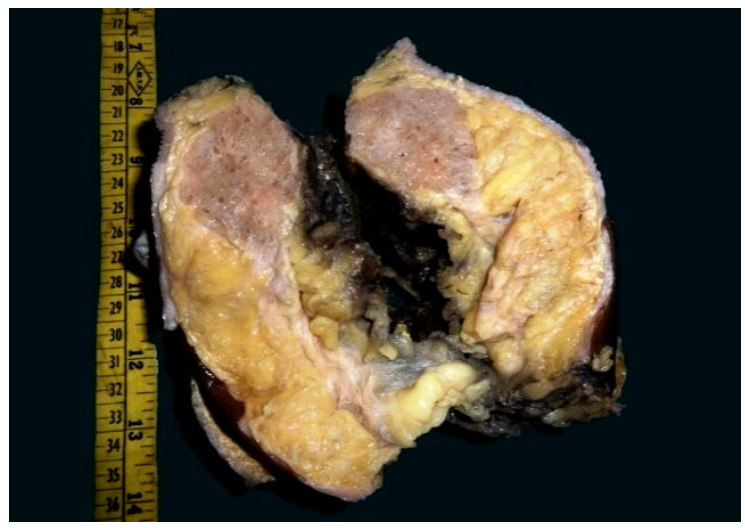

Figure.10. Well circumscribed glistening gelatinous growth

Mucinous Carcinoma

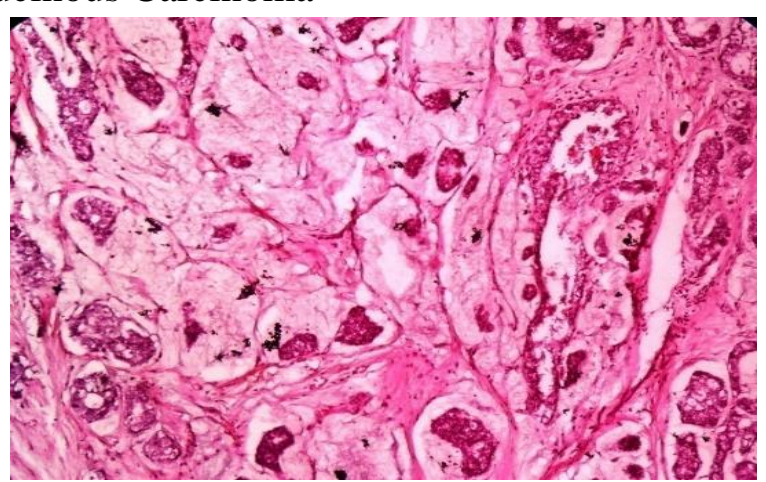

Figure 11. Tumor nests floating in pools of $\operatorname{mucin}(400 x)$

\section{Intra cystic papillary carcinoma}

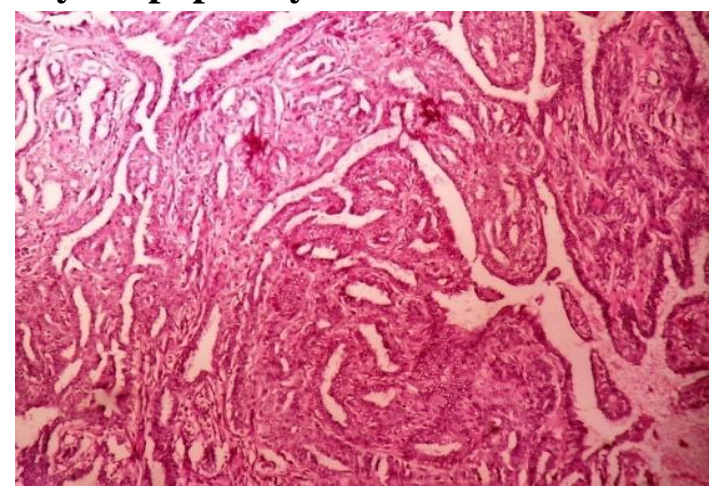

Figure 17 Microscopy -100x

\section{Lymphovascular Invasion}

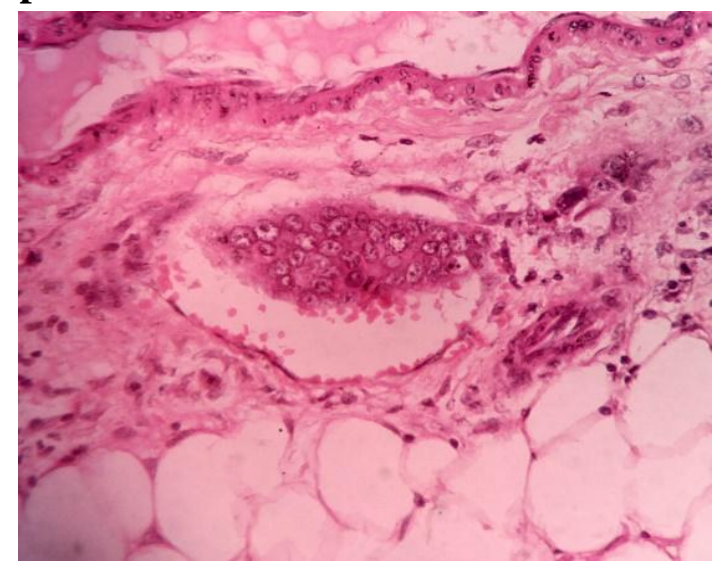

Figure 19 Microscopy 400X.

\section{Discussion}

Breast cancer is the most common cancer in the urban women and second common cancer in rural women. It is a heterogeneous disease with varying clinical and pathological presentation.

We can reduce the mortality of breast cancer by early detection, appropriate management and targeted therapies. Many theories underlie the pathogenesis of breast cancer and there are many prognostic factors including histological subtypes, grade, lymph node status, lymphovascular invasion, lymphocytic response, necrosis and skin infiltration.

Madras Medical College being a tertiary care center, among the surgical specimens received, breast specimens include $6.33 \%$ of all cases. Malignant breast tumors constituted $40.5 \%$ of all the breast specimens received.

The youngest age presented with invasive ductal carcinoma was 30 years and oldest age reported was 75 years with 49 as median age of 
presentation. This compared with study by Micello et al, ${ }^{[3]}$ Carreno et $\mathrm{al},{ }^{[4]} \mathrm{Hu}$ et $\mathrm{al},{ }^{[5]}$ Honma et $\mathrm{al}^{[6]}$ showed that in India there is a change in trend towards younger age group in the recent years. Breast cancer seems to be more common in the younger age group in India and $52 \%$ of all women suffering from breast cancer in Mumbai are between 40 and 49 years of age ${ }^{[7-11]}$. The highest incidence of breast cancer was reported in 41 to 50 years age group. This is in concurrence with the study done by RajeshSingh Laishram et al. ${ }^{[12]}$

Among the histological types, Invasive ductal carcinoma NOS type comprised the most common with $93.3 \%$. This correlated with the study done by Albrektsen et al, ${ }^{[13]}$ Shirley SE et al ${ }^{[14]}$ and AM Dauda et al. ${ }^{[15]}$ The incidence of IDC NOS type is higher in Indian women (89.62\%) compared to that of western women accounting for the poor prognosis. According to Shet $\mathrm{T}$ et al study, the incidence of mucinous carcinoma is $2 \%$ to $3 \%$ and also intracystic papillary carcinoma commonly seen in our Indian population which is comparable to our study. ${ }^{[16]}$

Majority of the breast carcinomas were T2 stage which is similar to the study done by Lakmini et $\mathrm{al}^{[17]}$. But comparing with the study by Christine $\mathrm{L}^{[18]}$ and Carter et al the proportion of $\mathrm{T} 2$ in Indian population $(70.28 \%)$ is higher than in Western population (55.4\%).

The Grade II tumors were more common than other grades of breast cancers. This observation coincides with the study done by QiuJ et al ${ }^{[19]}$ ,Careyet al ${ }^{[20]}$ and G GVanden Eynden et $\mathrm{al}^{[21]}$.

Fifty eight percent of the cases showed lymph node metastasis and $37.6 \%$ cases with 1-3 nodes positive. These datacoincides with the study done by Jun Qiuet $\mathrm{al}^{[13]}$ and S E Shirley et $\mathrm{al}^{[9]}$ who reported nodal metastasis in $60.32 \%$ and $75.7 \%$ of their cases.

In our study there was lymphocytic infiltration in $74.5 \%$, skin infiltration in $6.10 \%$ and necrosis in $47.3 \%$ of the cases, but there was $33 \%$ skin infiltration reported in the study conducted by
Chanda Bewtra et al ${ }^{[16]}$ and $38.1 \%$ necrosis in the study conducted by Gloria Perio et al. ${ }^{[17]}$

\section{Conclusion}

Invasive carcinoma is the most common type. Incidence is more common at younger age group as compared to western population. More than half of the patients presented with lesser tumor size, lymph nodal metastasis, lesser grade and more lymphocytic response. This study population had better prognostic factors.

\section{References}

1. Parkin DM, Bray F, Ferlay J, Pisani P: Esti mating the world cancer burden. Globocan 2000. Int J Cancer 2001; 94:153-156.

2. Balkrishna B Yeole, A P Kurkure. An Epidemiological Assessment of Increasing Incidence and Trends in Breast Cancer in Mumbai and Other Sites in India, during the Last Two Decades. Asian Pacific J Cancer Prev2003; 4:51-56.

3. Micello D, Marando A, Sahnane N et al. Androgen receptor is frequently expressed in HER2 positive, ER/PR negative breast cancers. Virchows Arch. 2010;457(4):467476.

4. Carreno G, Del Caser JM et al. Local recurrence after mastectomy for breast cancer: analysis of clinicopathological, biological and prognostic characteristics. Breast Cancer Res Treat. 2007;102(1):6173.

5. $\mathrm{Hu} \mathrm{R}$, Dawood S, Holmes $\mathrm{MD}$ et al. Androgen receptor expression and breast cancer survival in postmenopausal women. Clin Cancer Res.2011;17(7):1867-1874.

6. Honma N, Horii R, Iwase $\mathrm{T}$ et al. Clinical importance of androgen receptor in breast cancer patients treated with adjuvant tamoxifen monotherapy. Breast cancer.2012 Feb.

7. Khokhar A. Breast cancer in India: Where do we stand and where do we go? Asian Pac J Cancer Prev2012;13:4861-6. 
8. Chopra B, Kaur V, Singh K, Verma M, Singh S, Singh A. Age shift: breast cancer is occurring in younger age groups-is it true? Clin Cancer Investig J2014; 3: 526-29.

9. Thangjam S, Laishram RS, Debnath $\mathrm{K}$. Breast carcinoma in young females below the age of 40 years: a histopathological perspective. South Asian J Cancer 2014; 3: 97-100.

10. Sandhu D, Sandhu S, Karwasra R, Marwah S. Profile of breast cancer patients at a tertiary care hospital in north India. Indian J Cancer 2010; 47: 16-22.

11. Kakarala M, Rozek L, Cote M, Liyanage S, Brenner DE. Breast cancer histology and receptor status characterization in Asian Indian and Pakistani women in the U.S.: a SEER analysis. BMC Cancer 2010; 10: 191.

12. 12.Rajesh Singh Laishram, Gegong Jongkey, Sharmila Laishram, Clinico Morphological Patterns of Breast Cancer in Manipur, India. International Journal of Pathology 2011; 9 (1): 40-43.

13. Albrektsen et al, Histological type and grade of breast cancer tumors by parity, age at birth, and time since birth: a register-based study in Norway. BMC Cancer 2010; 10: 226.

14. Shirley S E, Sinclair P A, Stennett M A et al, The pathology of breast cancer in Jamaica: The National Public Health Laboratory study. West Indian Med J. 2010;59 (2):177-81.

15. AM Dauda, M A Misauno and E O Ojo, Histopathological Types of Breast Cancer in Gombe, North Eastern Nigeria: A Seven-Year Review. Afr J Reprod Health 2011; 15(1):107-109

16. Shet $\mathrm{T}$ et al, Time to change the way we diagnose mucinous carcinomas of the breast. Hum Pathol2014;45:434-5.
17. Lakmini K B Mudduwa et al, Quick score of hormone receptor status of breast carcinoma: Correlation with the other clinicopathological prognostic parameters, Indian Journal of pathology and microbiology 2009; 52(2): 159-162.

18. Christine L.Carter, Carol Allen, Donald E. Henson, Relation of Tumor Size, Lymph Node Status, and Survivalin 24,740 Breast Cancer Cases.Cancer1989;63:181-187.

19. QiuJ, Yang R, RaoY, DuY, Kalembo FW, Risk Factors for Breast Cancer and Expression of Insulin-Like Growth Factor-2 (IGF-2) in Women with Breast Cancer in Wuhan City, China. PLoSONE2012; 7(5): e36497.

20. Carey LA, Perou C M, Livasy C A et al, Race, Breast cancer Subtypes, and survival in the Carolina breast cancer study, JAMA 2006; 295(21): 2492-2502.

21. GG Vanden Eynden, I Vander Auwera, SJ VanLaere, Distinguishing blood and lymph vessel invasion in breast cancer: prospective immunohistochemical study. Br J Cancer 200694 (11):1643-1649.

22. Chanda Bewtra et al, Clinicopathologic features of female breast cancer in Kumasi, Ghana, International Journal of Cancer Research. 2010; 6(3): 154-160

23. Glorioperio et al, Prognostic Implications of HER-2 Status in Steroid ReceptorPositive, Lymph Node-Negative Breast Carcinoma, Am J Clin Pathol 2007; 127: 780-786. 